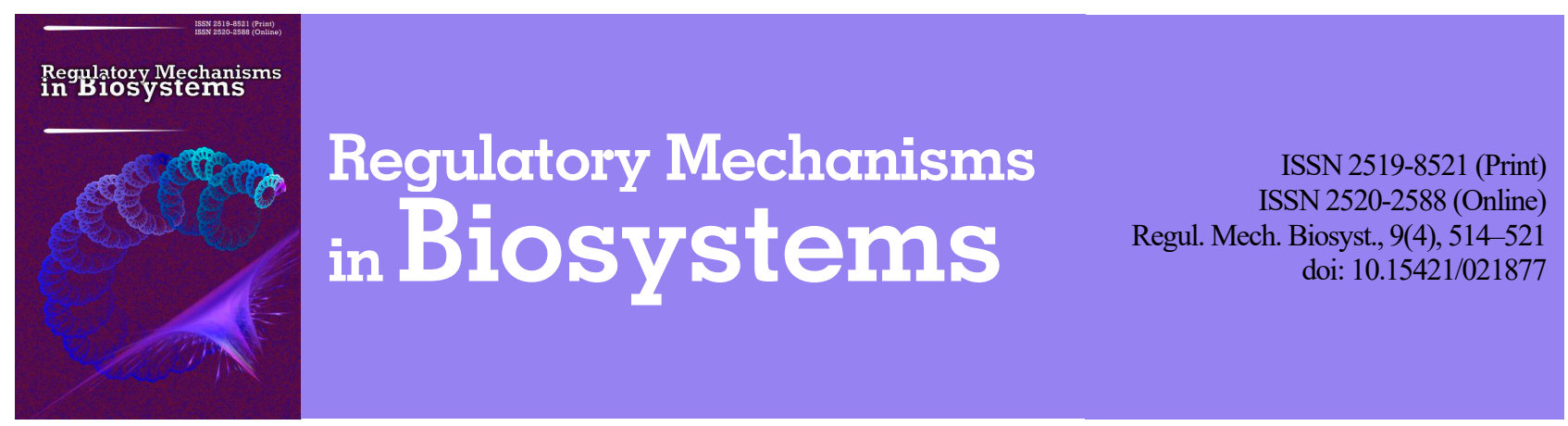

\title{
The bioelectric type of the visual area of the cerebral cortex of rats of all ages and sexes
}

\author{
V. V. Mizin*, V. P. Lyashenko*, S. M. Lukashov** \\ *Oles Honchar Dnipro National University, Dnipro, Ukraine \\ **Diagnostic and Treatment Scientific-Advisory Center "Headache", Dnipro, Ukraine
}

Article info

Received 13.09.2018

Received in revised form 22.10.2018

Accepted 25.10.2018

Oles Honchar Dnipro National University,

Gagarin av., 72

Dnipro, 49010, Ukraine.

$\mathrm{Tel} \cdot+38-097-834-83-11$

E-mail:

valeriyamv@gmail.com

Diagnostic and Treatment Scientific-Advisory

Center "Headache"

Soborna sq., 12

Dnipro, 49000, Ukraine.

Tel.: +38-056-246-65-55

E-mail:

dr.lukashev@gmail.com

\author{
Mizin, V. V., Lyashenko, V. P., \& Lukashov, S. M. (2018). The bioelectric type of the visual area of the cerebral cortex of rats of \\ all ages and sexes. Regulatory Mechanisms in Biosystems, 9(4), 514-521. doi:10.15421/021877
}

In the ontogenesis process, the cerebral cortex undergoes age-related changes. So far as, unlike practically all other systems of mammalian organs, the brain continues to develop and receive new functionality in the postnatal period. Thus with age, there are changes in the bioelectric characteristics of the neocortex. The purpose of the research is to determine the age and sex changes in the bioelectric activity of the cerebral visual cortex of male and female rats of different ages. In the article, we examined changes in absolute $\left(\mu \mathrm{V}^{2}\right)$ and normalized (\%) indicators of electrical activity of the visual area of rats of different sexes in four age groups: juvenile, young, mature, and presenile age. The research was carried out by the method of registration of bioelectric activity of electrocorticograms (ECoG). Results of multifactorial dispersion analysis of absolute and normalized ECoG indicators of the visual area of the cerebral cortex of rats of all ages showed that there were reliable changes in the frequency-amplitude characteristics of bioelectric activity related to age. At a young age, males have probably lower absolute and normalized power of the delta-rhythm and the normalized beta-like rhythm rate. There was a tendency of decrease in the theta-rhythm. As a result of this redistribution of rhythms a desynchronization of the electrical activity of young males was observed. Mature males have lower absolute power indicators than younger age groups. According to normalized indicators, a synchronization of rhythms of males in the mature age group was observed, which together with values of absolute power can indicate a decrease of the functional activity level of the neocortex and an increase of the influence of endogenous mechanisms on neuronal activity of the visual area of the cerebral cortex. In the presenile age, there was a desynchronization of rhythms. The indicators of an absolute and normalized power of females in the young age group pointed to the synchronization of the bioecoactivity of the neocortex. Among the low-frequency waves, thetarhythm rhythm dominated in the females of young age. In the mature and presenile age females, there was a probable increase in the percentage of normalized parameters of high-frequency beta waves. The predominance of this rhythm may indicate an increase of cortical tone. The correlation of values of absolute and normalized indicators of bioelectric activity affirmed the desynchronization of the ECoG rhythms of females of mature and presenile age. Sex differences are expressed by a decrease in the absolute power of all ECoG rhythms of the visual area of the cerebral cortex of females relative to males. The age-related changes occurred in a different way in rats of different sex. At a young age, males had desynchronization of rhythms, and females had synchronization, in the mature age it was vice versa. The age changes of the electric activity of the cerebral visual cortex of rats in our opinion may be largely associated with involutional changes of various neurotransmitter and hormonal systems.

Keywords: electrocorticogram; background electrical activity; neocortex; juvenile age; young age; mature age; presenile age

\section{Introduction}

The bioelectric activity of the cerebral cortex is one of the indicators of the functional state of the organism insofar as any external or internal factors that influence the body lead to a change in the bioelectric activity of the cerebrum, which in its turn reflects the interaction of excitatory and inhibitory processes of cells of the central nervous system. The frequency spectrum of bioelectric activity of the brain consists of rhythmic and arrhythmic variations. There are only low-frequency processes ranging from $10 \mathrm{~ms}$ to 10 seconds in the total electroencephalogram. The presence of various rhythms in the electroencephalogram (EEG) causes the ability of the slow variations of the electrical activity to repeat rhythmically (Vorob'eva \& Koljadko, 2007). The feature of space-time organization of rhythmic components of the electrocorticogram (ECoG), the analysis of background activity of the brain, allow determining the pattern of maturation of cortical structures of the cortex of a particular cortex zone in different age periods. Numerous examinations show that the electrical potentials of the cerebrum are related to information processes occurring in a particular part of the cerebrum. Inhibitory and excitatory effects correspond to the identified electrical potentials. Thus EEG is a result of a complex summation of the electrical potentials of many neurons that work independently to a large extent. It is well known that activating reticular cortical and limbic cortical systems cause an increase of the level of cerebrum functional activity (Andrzejewski, 2011; Man'kovskiy, 2013). Reverse changes are observed at activation of somnogenic, reticular cortical and thalamocortical systems. As the final effect of the action of these two systems is realized on the same cerebrum cortical systems, the level of functional activity is determined by the specific weight of the activity of each system in this situation (Meyer, 2014).

The neocortex is the largest structure of the mammals' cerebrum, which takes up about two-thirds of its total volume. It takes a central role in many functions including perception, decision-making, learning and memory (Zhang, 2006). At the beginning of the twentieth-century rats were used in numerous studies to analyze the role of individual areas of the cerebral cortex in behavioral reactions. In the late 40's Krieg made the first full description of the rat's cortical areas of the cerebrum 
on the basis of Broadmann's digital nomenclature. The nomenclature developed by Krieg was based mainly on the topographic similarity of primates' and rodents' cortical areas but did not take into account the cytoarchitectonic features. Further Zilles (1985) developed a stereotactic atlas of the rat's cerebral cortex. It provides a nomenclature independent of those previously developed on other species of animals. According to his nomenclature, the neocortex is divided into various cortical fields and zones. Many of these regions can be included in the functional mergings. At the moment, the rat's visual cortex which traditionally includes the following fields: 17, 18, 18a, attracts the special attention of researchers (according to Krieg). The occipital area is interesting because it does not contain any anatomical markers of delimitation in these areas (except the cortical striatum). However, neurophysiologists use the EEG method of recording different signal types with the help of electrodes for division into functional areas.

Different cortical zones of the cerebrum in the process of ontogenesis mature not at the same time, and the process of age changes continues after their absolute maturation. So far as unlike practically all other systems of mammalian organs, the cerebrum continues to develop and receive new functionality in the postnatal period. Recently, tnterest to role of postnatal cerebrum development in the etiological series of neurological diseases increases. The rat has long been recognized as a powerful model for studying neuropathology and the safety of the pharmacological treatment. But complex spatial and temporal changes occurring during neurodevelopment of rats remain undetermined (Lopes da Silva et al., 2009; Calabresea et al., 2013; Choi et al., 2015). During the study of the influence of various factors on the bioelectric activity of the cerebrum should one should take into account the age periodization to obtain more reliable results because during aging there occur changes in physiological functions, and sensitivity to adverse factors increases (Bradshaw et al., 2016). There are currently a lot of scientific works devoted to histological and bioelectric changes during the stages of early ontogenesis (Tarokh, et al., 2010; Makhmudova, 2013), but there are almost no works which reveal changes in the bioelectric activity of the rat's cerebral cortex in the process of long-term involution. Researches on age-related changes in the rat cerebral cortex can provide a unique idea of the normal course of neurodevelopment and allow scientists to distinguish normal changes in development from pathological ones. For example, there are two well-known histological atlases by Sherwood \& Timiras (1970) "A stereotaxic atlas of the developing rat brain" and Paxinos \& Ashwell's (2008) "Atlas of the developing rat nervous system". In the atlas by Sherwood-Timiras there are three postnatal age points (P10, P21 and P39), in other words, rats of 10, 21, and 39 days from birth, but in the atlas by Ashwell-Paxinos there is only one (P0). In 2011 Ramachandra \& Subramanian published "Atlas of the neonatal rat brain", which contains three postnatal age points (P1, P7 and P14). In literary sources, there is a comparison of the rat age to the human one. According to these, a rat 10-12 days of life in terms of maturity of neurogenesis and differentiation of neurons approximately corresponds to the age of a newborn infant (Semple et al., 2013). Rats aged P20-26 according to the degree of maturity of the nervous system correlate with children 2-6 years old, P32-36 days, especially cortical structures, can correlate with children at the age of the early prepubertal period, the rat puberty period lasts to P45-50. The maturity of the rat cerebrum by parameters such as myelinization and elimination of unnecessary connections occurs after P90 (Semple et al., 2013). During development, there are changes in the plasticity of the brain and functional alterations. Children's age is characterized by the intense formation of the central CNS (Semple et al, 2013). In the teenage period, there are significant changes in the limbic and prefrontal areas and also active neuronal and synaptic contraction of synapses and neurons, which is the reorganization of connections (Brenhouse \& Andersen, 2011; Buchman et al., 2011). For the adult period, the end of the formation of neural networks is characteristic (Andrzejewski et al., 2011; Choi et al., 2015). After the final formation of the structures of the cerebrum, in particular the neocortex, involutional changes continue in bioelectric activity and morpho-functional parameters.

Most authors usually describe the changes in ECoG values for rats of one sex, male rats. The decision to research males is conditioned by the aim of preventing the effects of cyclic changes in hormonal regu- lation that are present in females. Researchers have determined that climacteric and premenstrual syndromes in women include the deterioration of memory, reducing the ability to focus attention, increased emotionality, and depression (Mengler et al., 2014). Despite the relative autonomy of the cerebrum, other systems of the organism influence it, namely the important role in the development and support of its functions belongs to sex steroid hormones (Griffen, 2017). At early stages of ontogenesis, they provide an "organizing" action (Kuppers et al., 2000), controling the sexual differentiation of brain structures (Brockmann et al., 2011). In embryogenesis, testosterone affects the brain and forms structural and functional gender differences. But the development of the cerebrum depends on the effects of sex steroids in other periods of ontogenesis as well because, in the future, the effects of their influence are not reproduced or canceled. Hormones greatly influence the formation of mental status, emotions, memory, behaviour, and intelligence (Marshall et al., 2003). Changes of level and correlation of androgens, estrogens, and corticosteroids in the development process can be the cause of dysfunctions of brain regulatory systems (Wonders \& Anderson, 2006), and affect such essential components of brain development and functioning as myelinization processes, free radical oxidation, and apoptosis (Mengler et al., 2014; McDougal et al., 2018). Thus it is important to examine changes in electrical activity of the visual area of the cerebral cortex of rats not only in the context of age involution, but also taking into account the gender differences in these processes.

The purpose of the work to determine age and sex changes of indicators of bioelectric activity of the visual area of the cerebral cortex of male and female rats of different ages.

\section{Materials and methods}

Experiments were conducted on white nonlinear outbred male and female rats. There were 8 groups of rats depending on their age and sex: group I - males of the juvenile age of puberty $(n=15)$; group II - females of the juvenile age of puberty $(n=15)$; group III - males of the young age of the reproductive period $(n=14)$; group IV - females of the young age of the reproductive period $(n=14)$; group $\mathrm{V}-$ males of the mature age of the reproductive period $(n=14)$; group VI - females of the mature age of the reproductive period $(n=14)$; group VII - males of the presenile age of the period of ageing changes $(n=14)$; group VIII females of the presenile age of the period of ageing changes $(n=14)$ (Zapadnjuk, 1983). According to the rules of zoological hygiene, the animals which were involved in the experiment were quarantined. They were kept in standard conditions for laboratory animals: in illuminated premises with a constant temperature of $20-25^{\circ} \mathrm{C}$ and a humidity of $40-45 \%$, without limitation in drinking water.

The conditions of maintenance and the experiments performed on the rats conformed to the regulations of "European Convention for the Protection of Vertebrate Animals Used for Experiments and Other Scientific Purposes" (Strasbourg, 2005), "General ethical principles of experiments on animals", adopted by the Fifth National Congress on Bioethics (Kyiv, 2013).

The registration of the bioelectric activity of electrocorticotograms was carried out in conditions of an acute experiment. The surgical procedure of preparation for the experiment was made under the influence of anesthesia: thiopental sodium ( $50 \mathrm{mg} / \mathrm{kg}$ ) or 2-(ortho-chlorophenyl)2-(methylamino)-cyclohexanone hydrochloride, and ketamine hydrochloride $(20 \mathrm{mg} / \mathrm{kg})$ (Derymedved' et al., 2001). Anesthetic solution was injected into abdominal cavity of the rat. First, thiopental sodium was injected, after 5 minutes - ketamine. Then the animal was fixed in the stereotactic device and trepanation of the skull was performed. To obtain a clear separation of bioelectric activity of the visual area of the cerebral cortex, the head of a rat was rather forcibly fixed in three points (jaw and two auditory openings) (Buresh et al., 1962). Afterwards, we inserted into the neocortex a needle unipolar nichrome electrode (diameter $100 \mu \mathrm{m}$ ) coated varnish insulation except for the tip. Disposal of biopotentials was carried out according to the coordinates of atlas by Paxinos \& Watson (2013). Coordinates of the visual area of the cerebral cortex: bregma (B) - 3.8, lateral axis (L) -2.8 , intraoral axis (I) -2 . The grounding was carried out using an electrode fixed on the tail, and the indifferent electrode fixed on the auricle of the animal. The registra- 
tion of corticogram biopotentials was conducted using polygraph P6CH-01 (Ukraine) and standard electrophysiological equipment with a 16-bit ADC with a sampling frequency $512 \mathrm{~Hz}$ (Bogomoletz Institute of Physiology, Ukraine). In all records of bioelectric activity, the duration of the analysis period was $60 \mathrm{~s}$ with sampling frequency df equal to $0.1 \mathrm{~Hz}$. To remove edge effects we used the Hamming window. According to the recommendation of the International Federation of Electroencephalography and Clinical Neurophysiology, we used the following classification of oscillations in the ranges: delta $(\delta)-0.5-3.5 \mathrm{~Hz}$, theta $(\theta)-4-7 \mathrm{~Hz}$, alpha $(\alpha)-8-13 \mathrm{~Hz}$, beta $(\beta)-14-30 \mathrm{~Hz}$. Within common ranges, we analyzed the number of electroencephalographic waves by spectral (absolute) power $\left(\mu \mathrm{V}^{2}\right)$ and normalized (relative) power (\%) (Vorob'eva \& Koljadko, 2007). At the end of each experiment, the animals were decapitated.

The obtained results were analyzed statistically using the polyparametric dispersion analysis of the program Statistica 6.0 (StatSoft Inc., USA). We calculated the average arithmetic value and the average error $(\mathrm{M} \pm \mathrm{m})$. For a multiple comparison of samples, the Tukey test was used taking into account Bonferroni correction. Changes were considered probable at a significance level $\mathrm{P}<0.05$.

\section{Results}

The study of the bioelectric activity of the neocortex is one of the main methods for analyzing cerebrum activity because the frequencyamplitude spectrum of electrocorticograms reflects functional state of the brain. Biopotentials arise not only in response to afferent irritation but also reflect the continuous activity of the brain, which makes it possible to analyze the presence of age and sex changes of the electrical activity of the visual area of the neocortex.

The first stage of this work was registration and further analysis of native records of the background electrical activity of the visual area of the cerebral cortex of male rats in four age groups (Fig. 1).

3
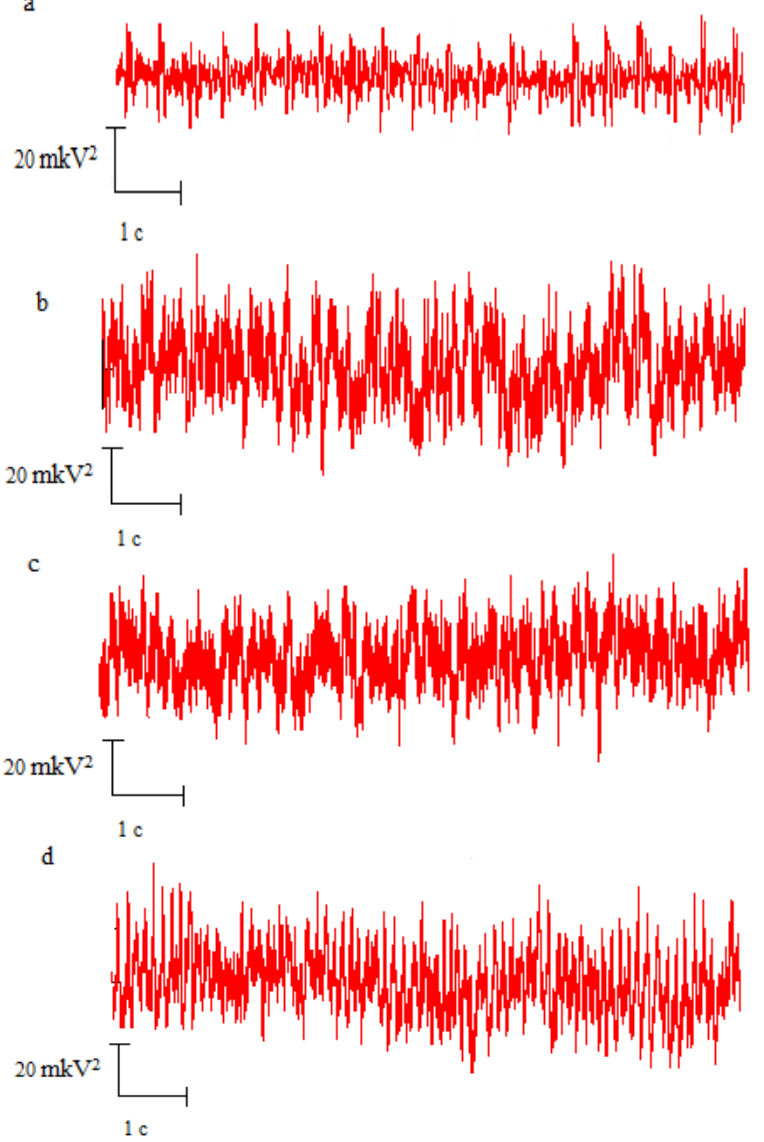

Fig. 1. The native recording of total electrical activity of the visual area of the cerebral cortex of rats: $a$ - juvenile rats, $b$-young rats, $c$-mature rats, $d$-presenile rats
Male rats of juvenile age (Fig. 1a), had an increase of wavelengths in the low-frequency range of delta rhythm. Instead, in young rats (Fig. 1b) waves of the high-frequency range of beta-like rhythm dominated. In the presenile age, males had an alpha-like rhythm (Fig. 1d). Then we analyzed the dynamics of the rhythms of background electrical activity of males in different age groups of the visual area of the cerebral cortex in absolute and normalized indicators.

To determine sex differences in age-related changes in the bioelectric activity of the visual cortex area, we registered background activity in female rats of different ages. Females of juvenile age had a lower wavelength relative to males, but the most expressed were waves of a low-frequency range (Fig. 2a). At a young age, the representation of the theta-rhythm waves increased (Fig. 2b). By the native recording of the total electrical activity of the visual area of the cerebral cortex of mature and presenile female (Fig. $2 c, d$ ) there was an increase of the wavelength of the high-frequency range, first of all, beta-like rhythm.

a
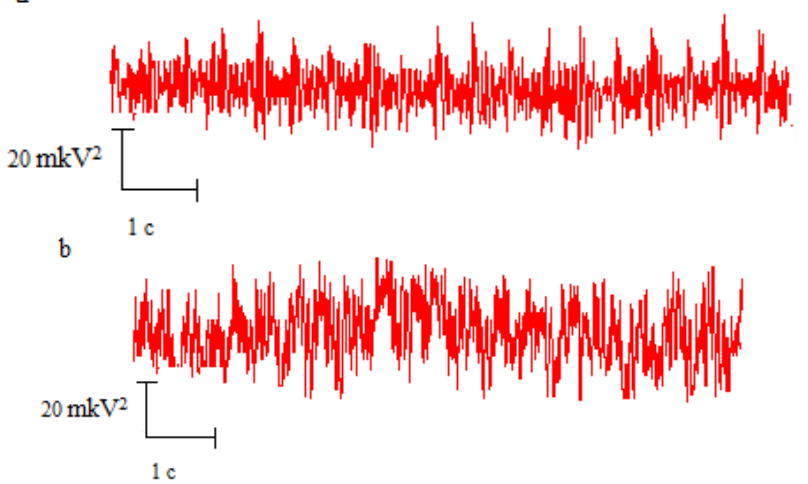

c
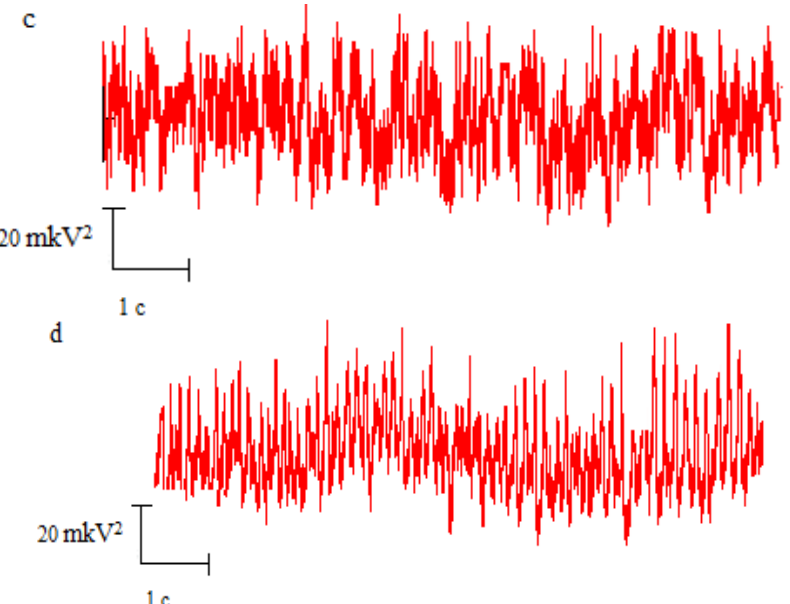

Fig. 2. Native recording of the total electrical activity of the visual area of the cerebral cortex of female: the designations are the same as in Fig. 1

We analyzed the indicators of the electrocorticogram of the visual area of the cerebral cortex of rats of different age and sex. Male rats of the juvenile age of puberty had an absolute index of delta rhythm of $105 \pm 25 \mu \mathrm{V}^{2}$ (Fig. 3). In other age groups, this indicator was probably lower in relation to the juvenile group, so this indicator in young rats was lower by $89.3 \%$, in mature - by $87.2 \%$, and presenile - by $69.0 \%$. There was a tendency to decrease in the absolute index of delta-rhythm of mature rats compared to those of a young age. In presenile males the delta rhythm rate was significantly higher by 2.8 times relative to the rats of the young age of the reproductive period. Value indicators of the absolute power of low-frequency high-amplitude theta-rhythm had wavelike age-related changes. In the juvenile age of puberty, males had the absolute power of the theta-rhythm $19.18 \pm 4.38 \mu \mathrm{V}^{2}$. This index of young males was $35.5 \%$ lower for males of juvenile age. Probably there was a lower absolute index of bioelectric activity of the theta-rhythm of the visual area of the cerebral cortex of mature males compared to this indicator of juvenile males. In the presenile age, male rats this indicator was 3.6 and 2.3 times lower relative to the males of the juvenile and 
young age, respectively, as well as 2.6 times higher relative to the values of the indicators of mature age.

The state of the visual area of the cerebral cortex was also characterized by the high-alpha rhythm, but it is a characteristic component of only the human electrocorticogram. In rats, this rhythm is represented by a similar alpha-like activity. The absolute power indicator of the alpha-like rhythm of the juvenile group was significantly higher among all groups and was $41.2 \pm 17.1 \mu \mathrm{V}^{2}$. As for the juvenile group, the power of the alpha-like rhythm decreased by 2.7 times at the young age, and by 13.6 times in the mature age. The absolute power index of the alphalike rhythm of the visual area of the cerebral cortex of the males of the presenile age is likely to be 1.6 times lower than that of males of the juvenile age and there was a tendency for an increase of $71.6 \%$ and 8.0 times relative to the rats of the young and the mature age respectively. The beta-like activity of the visual area of the cerebral cortex of male rats in the juvenile and the young age had the similar values of absolute power indices, exactly $77.5 \pm 25.1$ and $78.5 \pm 18.2 \mu \mathrm{V}^{2}$ respectively. However, in the mature and the presenile age we observed a probable decrease in the value of absolute power. The males of mature age had an absolute power index significantly lower at 10.4 and 10.5 times relative to the males of the juvenile and young age. In the presenile age, there was a tendency to increase in this indicator relative to the mature age group, as well as a probable decrease compared to the values of males of the juvenile and young age. By all indicators of the absolute power of bioelectric activity of the visual area of the cerebral cortex the highest values of the indicators among all groups were inherent to males of the juvenile age of puberty, and in the mature age, the data were probably the lowest.

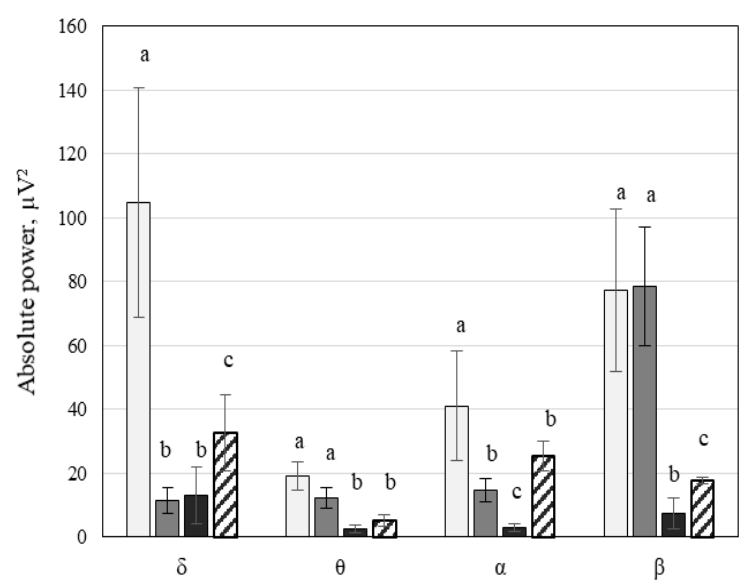

Fig. 3. Changes of the absolute index of bioelectric activity of the visual area of the cerebral cortex of male rats of different age groups $(M \pm m, n=14)$ : white colour - juvenile rats, grey colour young rats, black colour - rats of mature age, dashed - rats of presenile age; values marked with different letter indexes $(a, b, c)$ statistically are significantly different $(\mathrm{P}<0.05)$

Age changes in the indicators of the absolute power of the bioelectric activity of the visual area of the cerebral cortex of females occurred as follows (Fig. 4). The females of the juvenile age had the absolute power of the delta-rhythm $6.6 \pm 1.5 \mu \mathrm{V}^{2}$, which is significantly lower than that of the males of the given age. At a young age, this indicator was likely to increase by $98 \%$ in relation to the females in the previous group, and there was a tendency to increase by $16.3 \%$ for the males of the corresponding age. In mature females the value of the absolute power of the low-frequency delta-rhythm was $12.8 \pm 4.4 \mu \mathrm{V}^{2}$ which is similar to the level of the power of this rhythm in the groups of young females and mature males. In the fourth age group of females, the absolute power of the delta-rhythm probably decreased to the level of that of females in the juvenile age (first age group). The value of the absolute power of the females in this group was 4.8 times lower than that of the males of this age group. The absolute power of the theta-rhythm of the females in the juvenile age was probably 6.2 times lower than that of the males in the juvenile age. At a young age, the power of this rhythm increased 10.4 and 2.6 times in relation to the females of the previous age group and in relation to males of the corresponding age. In the females in the third age group, the power of the theta-rhythm decreased significantly in relation to the previous two age groups and the males of the mature age. In the presenile age, the females tended to show a decrease in the absolute power of the theta-rhythm of the visual cortex area relative to the females in the previous three age groups and the males of the corresponding age. The females of presenile age subject to ageing related changes had the lowest absolute power of theta-rhythm among all age groups of both sexes, and it was $1.33 \pm 0.5 \mu \mathrm{V}^{2}$.

The power of the alpha-like rhythm of juvenile females was probably lower compared to males of this age. At a young age, this indicator increased 2.6 times in relation to the first age group females and was significantly lower in young males. In females of mature and presenile age, the absolute index of alpha-like rhythm was likely to be lower in relation to the young females of reproductive age and the males of the corresponding age. The beta-like activity was the most pronounced in the three age groups of the females. In the juvenile age, the females had probably lower beta-like activity relative to the males in this age group. With age, there was an increase in the absolute power of the beta-like rhythm of the visual area of the cerebral cortex. The females in the young age had the indicator of this rhythm 12 times higher in relation to the females in the juvenile age but lower than the males in the young age group. In the mature females there was a higher value of absolute power compared with the previous two age groups of the females and the males in the mature age. Probably a higher rate of beta-rhythm power was observed in females of the presenile age subject to agerelated changes. The absolute power of this rhythm was significantly 93.2 and 2.4 times higher compared to the juvenile and mature females, respectively. Compared to the males in this age group, the females of the presenile age had a beta-like rhythm power 11.5 times higher.

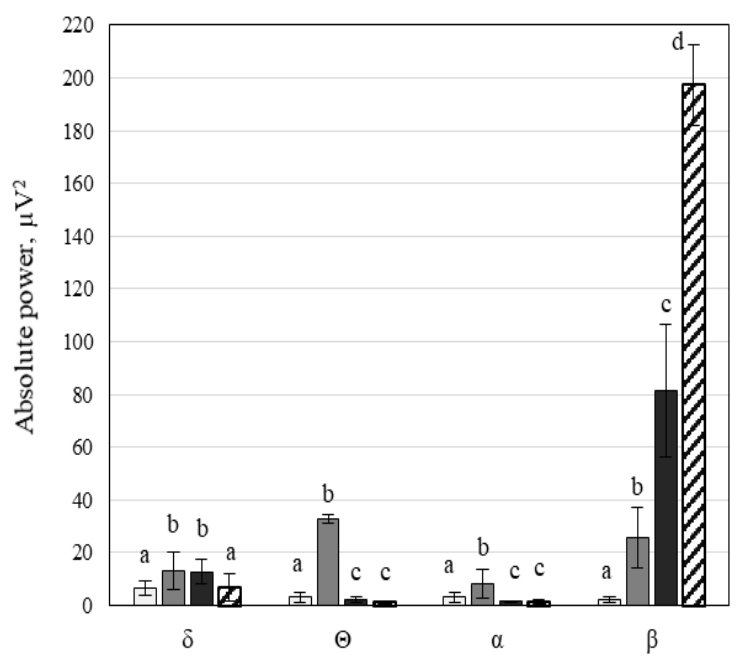

Fig.4. Changes of the absolute index of bioelectric activity of the visual area of the cerebral cortex of female rats of different age groups ( $M \pm m, n=14)$ : the designations are the same as in Fig. 3

The obtained values of absolute indicators of bioelectric activity of the visual area of the cerebral cortex of rats showed that there were sex and age differences. In the males were observed wave-like age-related changes, the lowest absolute power of bioelectric rhythms inherent in rats of the mature age of the reproductive period. Among the four age groups, the males of the juvenile age had a high level of power of all rhythms of the cerebral cortex. Sex differences were characterized by a significantly lower indicator of the absolute power of bioelectric activity of the female neocortex. With the age of females, the absolute power of all rhythms was reduced, except the beta-like activity. In mature and presenile age females, the indicator of the absolute power of the beta-like rhythm was higher compared to males of the same age and in females of juvenile and young age.

Besides indicators of the absolute power of bioelectric activity of the visual area of the cerebral cortex, we analyzed the normalized parameters of this area of rats. The obtained results of the research indicate the prevalence of delta-rhythm of the visual area of the cerebral cortex of males in three age groups: juvenile, mature, and presenile (Fig. 5). 
So at the juvenile age, the normalized power of the delta-rhythm was $42.0 \%$. The normalized power of high-frequency rhythms of bioelectric activity of the male neocortex was $16.9 \%$ (alpha-like rhythm) and $33.1 \%$ (beta-like rhythm). That is, the percentage relation between low and high-frequency rhythms was almost equal. In the young age, the normalized delta and theta rhythm indicators, as well as the alpha-like rhythm, were $9.5 \%, 11.3 \%$, and $12.6 \%$, respectively. The normalized indicator of the beta-rhythm was significantly higher than that of the previous age group. Such a prevalence of high-frequency electrical activity in the visual area of the cerebral cortex of young male rats pointed to the presence of desynchronization of electrical oscillations.

According to normalized indicators of bioelectric activity of the cerebral cortex of mature males in the reproductive period low-frequency rhythms prevailed. The value of the normalized indicator of the deltarhythm was $47.6 \%$, which was likely to be higher compared to young males. Almost the same percentage was occupied by the power of theta and alpha rhythms. Probably, the value of the normalized beta-rhythm indicator of mature males was 2.4 times lower compared to the young age group. The obtained results indicate the synchronization of the bio-electric rhythms of the visual area of the cerebral cortex of the rats in the mature age group relative to the indicators of young rats. In the presenile age, delta-rhythm was the most pronounced. The percentage representation of the theta-rhythm in the fourth age group was 1.7 times lower than the third group. In males of this age, the manifestation of desynchronization was due to the high level of the alpha-like rhythm (32.3\%) and beta-like rhythm (22.5\%).
Both in the absolute and normalized indicator, low-frequency rhythms in the neocortex dominated in females of juvenile and young age (Fig. 6). In females of the juvenile age, $44.1 \%$ of the total electrical activity was occupied by delta-rhythm. For the low-frequency theta-rhythm, the high value of the normalized indicator is characteristic $-21.0 \%$. In the group of young females, the value of the normalized delta-rhythm is likely to be lower in relation to the previous age group instead, the percentage part of the theta-rhythm increased to $41.4 \%$. The value of the normalized indicator of the bioelectric activity of the beta-type rhythm in the second age group increased 2.3 times compared with the results of juvenile females. In comparison with males of young age, this indicator in females is twice lower. In general, the group of young females has an almost equal ratio between normalized indicators of low-frequency and high-frequency rhythms. In the mature and presenile age rats, there was a probable decrease in the percentage of the activity of the delta-rhythm compared to the females in the juvenile age group and males of the corresponding age. The high-frequency alpha-like rhythm of females of the III and IV age groups is probably lower, and the beta-like rhythm is significantly higher in comparison with the females of the other two groups and male rats of the corresponding age. In the mature age, the beta-like rhythm was $83.7 \%$, and in the presenile $-95.3 \%$. The reduction of the alpha-like activity and the prevalence of the beta-like activity can indicate the anxiety and nervous tension of the animal. By normalized indicators of bioelectric activity of the visual area of the cerebral cortex, females of mature and presenile age showed desynchronization of rhythms.

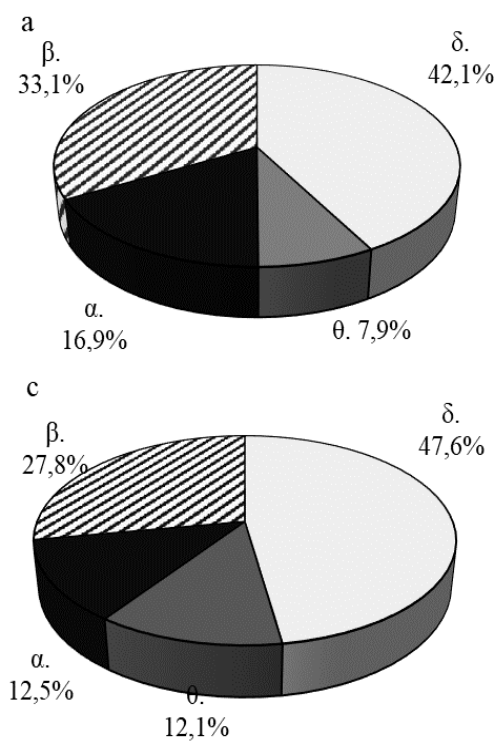

b

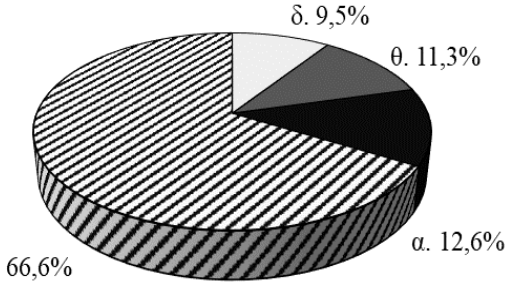

d

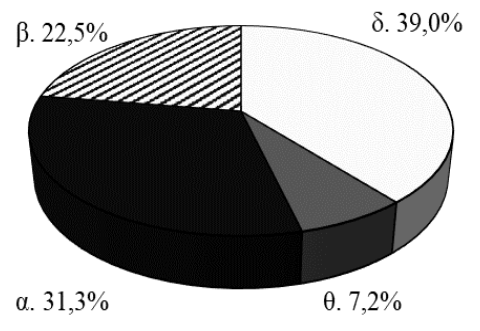

Fig. 5. Changes in the normalized indicator of the bioelectric activity of the visual area of the cerebral cortex of male rats of different age groups (\%): $a$ - juvenile rats, $b$-young rats, $c$ - rats of mature age, $d$-rats of presenile age; white colour - the absolute index of delta-rhythm, grey - the absolute index of theta-rhythm, black - the absolute index of alpha-like activity of the cerebral cortex, dashed - the absolute index of beta-like activity of the cerebral cortex

The obtained values of normalized indicators of the bioelectric activity of the visual area of the cerebral cortex of rats showed sex and age differences. In males of juvenile age, the percentage ratio of the total value of low-frequency and high-frequency rhythms of the ECoG was similar. In the group of males, we observed the synchronization of the neocortex rhythms of the electrical activity. At the young age, the betalike activity of the cerebral cortex of male rats was prevalent, and there was the desynchronization of rhythms. In the presenile males, the desynchronization of the rhythms of the visual area of the cerebral cortex was caused by the prevalence of alpha-like rhythm. In females of the juvenile age, unlike males in this age group, there was a percentage prevalence of low-frequency waves of electrical activity in the visual area of the cerebral cortex. At the young age, the level of low-frequency and highfrequency rhythms were almost in the same ratio. In groups of females of the mature and presenile age, the desynchronization of rhythms was probably due to the predominance of beta-like activity. Such a redistribution of normalized indicators of bioelectric activity of the visual area of the cerebral cortex of females probably differed from the age-related changes in the parameters of males.

\section{Discussion}

In rats, the basic processes of differentiation of the cortex occur in the postnatal period. These processes are characterized by changes in morphological, electrophysiological properties and interconnections (Marshall et al., 2003; Mengler et al., 2014). During development, there are changes in the plasticity of the brain and functional rearrangements: the childhood period is characterized by intensive CNS formation (Semple et al., 2013); in the teenage period, there are significant changes in the limbic and prefrontal areas, as well as active neuronal and synaptic pruning (reduction of synapses and neurons), therefore the reorganization of connections (Brenhouse \& Andersen, 2011); the adult period is marked by the more complete formation of neural networks (Andrzejewski et al., 2011; Choi et al., 2015). In the process of ontogenesis, there are changes 
in the balance and metabolism of neurotransmitters (gamma-aminobutyric acid, glutamate, dopamine, serotonin, acetylcholine, etc.) (Bachinskaya, 2010), which provide electrical activity and interaction of neurons with each other. Also, the processes of development in astrocytes regu-
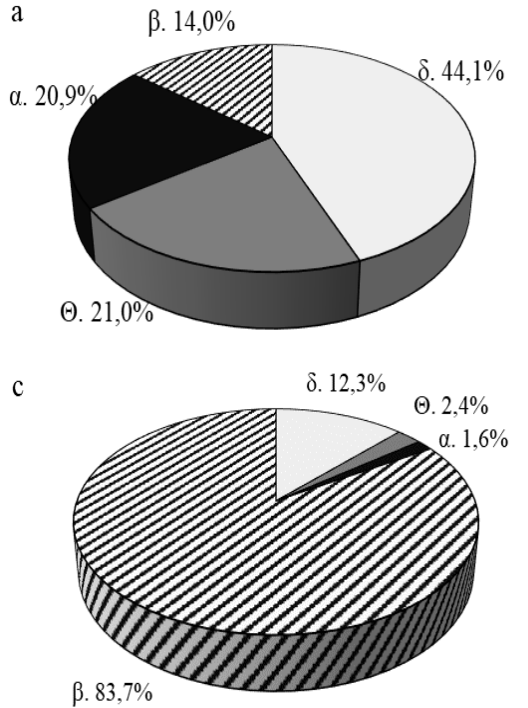

late the expression of metabotropic glutamate receptors mGluR5, which implies a fundamental difference in the transmission of signals between neurons in the immature brain and the brain of an adult organism (Sun et al., 2013).

$\mathrm{b}$

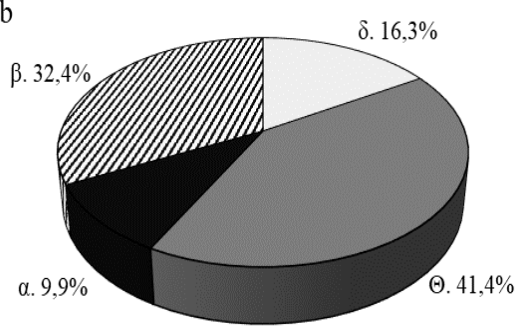

d

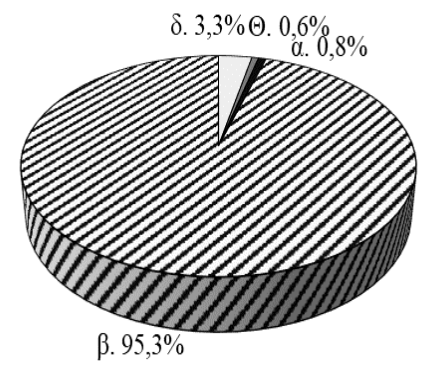

Fig.6. Changes in the normalized indicator of the bioelectric activity of the visual area

of the cerebral cortex of female rats of different age groups, \%: the designations are the same as in Fig. 5

The first fluctuations of EEG in rats were registered by some authors only on the 3-4th day of postnatal development, at the same time, the spontaneous rhythm of this period is characterized by instability and low amplitude compared with noise (Tucker et al., 2009). The registration of the EEG of rats at the age from 4 to 16 weeks in a chronic experiment showed that the delta-rhythm of EEG reaches its greatest development at the age of 4 weeks, while the theta-rhythm - from the 5th week of life (Naber et al., 2000). Other authors showed that after 19 days of life the rhythms of EEG of rats do not have systematic differences from those in the EEG of adult animals, both according to visual assessments and on the basis of computer analysis of the record. At this age, ECoG of rats acquires the importance of the frequency and amplitude characterristic of adult rats (Gao et al., 2015). However, there is evidence that this concept is not entirely true, and the differences in rhythms continue to change and mature after adolescence in animals and humans (Gradwohl et al., 2015).

Some authors showed (Murzin et al., 2015; Berchenko et al., 2016) that delta-activity and rhythm synchronization are prevalent in on electrocorticograms of juvenile and young rats. According to some studies (Chaus et al., 2008; Turic'ka et al., 2016), indicators of the power of the delta-rhythm of bioelectric activity of the cerebral cortex of control animals in percentages fluctuated within 73.2-87.6\%. Also, works of these authors indicate a decrease in the absolute power of bioelectric activity in all rhythms starting at 7 months, which is similar to our results. Data of multifactorial dispersion analysis of absolute and normalized indicators of ECoG of the visual area of the cortex of different age groups showed that with age there were probably changes in the frequencyamplitude characteristics of the bioelectric activity. In the group of juvenile males, we observed the synchronization of electric oscillations due to the growth of absolute and normalized low-frequency wavelengths with the prevalence of delta-rhythm. At a young age, there was probably lower absolute and normalized power of the delta-rhythm and we observed a tendency to decrease in the theta-rhythm. The normalized indicator of beta-like rhythm increased. As a result of this redistribution of rhythms in young males, the desynchronization of electrical activity was observed. Indicators of the absolute power of the visual cortex area of males are probably lower in comparison with the previous two groups of rats. According to normalized indicators of this age group, the synchronization of rhythms was observed, which together with the values of absolute power may indicate a decrease in the level of functional activity of the neocortex, and increase the influence of endogenous mechanisms on the neuronal activity of the visual area of the cerebral cortex (Tarokh et al., 2010; Brockmann et al., 2011). In the presenile age rats, we observed the desynchronization of rhythms on account of the growth of normalized power of high-frequency range against the background of lowering these indicators in the low-frequency range.

Probable age and sex changes in the electrical activity of the visual area of the cerebral cortex were found in female rats. Indicators of absolute and normalized power pointed to the synchronization of the bioelectric activity of the neocortex of females of the juvenile and young age. Among the waves of the low-frequency range in juvenile females deltarhythm dominated, and at the young age - the theta-rhythm. We found that the theta-rhythm arises in the electrocorticogram of males with unconditioned reflex and conditioned reflex activity and is one of the components of the orientational animal reaction. This rhythm also increases with stress reactions (Kocharyan et al., 2008; Carlen et al., 2009). In mature and presenile age rats, the percentage of normalized high-frequency rhythm rate probably increased, namely beta-like rhythm. The prevalence of this rhythm may indicate an increase in cortical tone. Such a ratio of values of absolute and normalized indicators of bioelectric activity indicated the desynchronization of rhythms. Sex differences are expressed by the decrease in the absolute power of all rhythms of the ECoG of the visual area of the cerebral cortex of females relative to males. Also, agerelated changes were different. In males at a young age, there was a desynchronization of rhythms, whereas in females, on the contrary, rhythms were synchronized and low-frequency waves prevailed. In the mature rats, males were characterized by the presence of low-frequency delta-rhythms and the synchronization of neocortex electrical activity. There is a desynchronization of rhythms in females of mature age. Presenile age rats of both sexes had a desynchronization of the bioelectric activity of the cerebral cortex, but due to various high-frequency rhythms.

In our opinion, the age-related changes in the electrical activity of the visual area of the cerebral cortex of rats can be largely associated with involutional changes in the various mediator and hormonal systems. For now, there is a lot of data about the importance of neurotransmitters in regulating normal aging and age-related pathologies (Man'kovskiy \& Kuznetsova, 2013; Howe et al., 2017; Obermayer et al., 2017). The obtained results of modulation of bioelectric activity indicators can be associated with the reduction of components of the dopamine system and the dopamine carrier. It was determined that the number of noradrenergic neurons decreases with age, decreases the content and activity of the peptides such as platelet factor, insulin-like factor, and fibroblast growth 
factor (Shumilova et al., 2015). The cholinergic and serotonergic innervation of the cerebral cortex decreases with age (Howe et al., 2017; Obermayer et al., 2017), cholesterol is redistributed due to increased intracellular cholesterol, which leads to a reduction in the synthesis of cholesterol, and as a consequence the decrease in the synthesis of hormones (Man'kovskiy \& Kuznetsova, 2013). In our previous works (Mizin et al., 2017, 2018), we obtained similar results. It is determined that the corticosterone and dehydroepiandrosterone sulfate content decreased with age in the serum of blood of rats of different sexes.

\section{Conclusions}

The results of the experiment prove the presence of age-related changes in the bioelectric indicators of the visual area of the cerebral cortex of rats. By frequency-amplitude characteristics of the electrical activity, low-frequency waves dominated, namely the delta-rhythm, and the synchronization of electrical oscillations was observed. With age, absolute power probably decreased, which is most likely associated with a decrease of the components of the dopamine system and carriers of dopamine, as well as a decrease in the number of noradrenergic neurons. At a young age, there was a redistribution of normalized power towards the high-frequency wavelength range. The absolute power of the visual cortex area of males was significantly lower in comparison with the previous two groups of rats. According to the normalized indicators of this age group, we observed the synchronization of rhythms. In males of the presenile age, we observed the desynchronization of rhythms due to the growth of normalized power of the high-frequency range and decrease in the power in the low-frequency range. By absolute and normalized indicators of the power in juvenile and young females, we observed the synchronization of the electrical activity of the visual cortex area. In females of mature and presenile age, the normalized rate of beta-like rhythm probably increased. By the ratio of values of absolute and normalized indicators of bioelectric activity of the cerebral cortex in females, we observed the desynchronization of rhythms. Probably gender differences are expressed by a decrease in the absolute power of all rhythms of the ECoG of the visual area of the cerebral cortex of females compared with males.

\section{References}

Agadzhanjan, N. A. (1983). Adaptacija i rezervy organizma [Adaptation and body reserves]. Fizkul'tura i Sport, Moscow (in Russian).

Andrzejewski, M. E., Schochet, T. L., Feit, E. C., Harris, R., McKee, B. L., \& Kelley, A. E. (2011). A comparison of adult and adolescent rat behavior in operant learning, extinction, and behavioral inhibition paradigms. Behavioral Neuroscience, 125(1), 93-105.

Bachinskaya, N. Y. (2010). Sindrom umerennykh kognitivnykh narusheniy [Syndrome of moderate cognitive impairment]. Neyro News: Psikhonevrologiya i Neyropsikhiatriya, 2(1), 12-17 (in Russian).

Berchenko, O. G., Bevzyuk, D. O., Levicheva, N. O., \& Koladko, S. P. (2016). Neyrofiziolohichni mekhanizi formu nevimichnoyi zalezhnosti samo stymulyatsiyeyu pozytyvno emotsiynykh zon mozhu u shchuriv [Neurophysiological mechanisms of formation of non-chemical dependence through selfstimulation of positive emotiogenic areas of rats' brains]. Visnyk of Dnipropetrovsk University, Biology, Ecology, 24(2), 270-275 (in Ukrainian).

Bradshaw, S. E., Agster, V. L., Waterhouse, B. D., \& McGauyhy, J. A. (2016). Agerelated changes in prefrontal nonepinephrive transporter density: The basis for improved cognitive flexibility after low closes of atomoxetine in adolescent rats. Brain Research, 1641(B), 245-257.

Brenhouse, H. C., \& Andersen, S. L. (2011). Developmental trajectories during adolescence in males and females: A cross-species understanding of underlying brain changes. Neuroscience and Biobehavioral Reviews, 35(8), 1687-1703.

Brockmann, M. D., Poschel, B., Cichon, N., \& Hanganu-Opatz, I. L. (2011). Coupled oscillations mediate directed interactions between prefrontal cortex and hippocampus of the neonatal rat. Neuron, 71, 332-347.

Buchmann, A., Ringli, M., Kurth, S., Schaerer, M., Geiger, A., Jenni, O. G., \& Huber, R. (2011). EEG sleep slow-wave activity as a mirror of cortical maturation. Cerebral Cortex, 21, 607-615.

Buresh, J., Petran', M., \& Zahar, I. (1962). Jelektrofiziologicheskie metody isledovanija [Electrophysiological methods of investigation]. Izdatel'stvo Inostrannoj Literatury, Moscow (in Russian).
Calabresea, E., Badeaa, A., Watsonc, C., \& Johnson, A. G. (2013). A quantitative magnetic resonance histology atlas of postnatal rat brain development with regional estimates of growth and variability. NeuroImage, 71(1), 196-206.

Chaus, G. G., Chaus, T. G., \& Lyashenko, V. P. (2008). Dynamika pokaznykiv bioelektrychnoyi aktyvnosti kory holovnoho mozku shchuriv za umov stresu i zastosuvannya hidazepamu [Dynamics of indicators of bioelectric activity of rat cerebral cortex under conditions of stress and the use of hydazepam]. Visnyk of Dnipropetrovsk University, Biology, Ecology, 16(1), 210-215 (in Ukrainian).

Choi, H., Choi, Y., Kim, K. W., Kang, H., Hwang, D. W., Kim, E. E., Chung, J. C., \& Lee, D. S. (2015). Maturation of metabolic connectivity of the adolescent rat brain. eLife, 4, e11571.

Derimedved', L. V., Percev, I. M., \& Shuvalova, E. V. (2001). Vzaimodejstvie lekarstv $\mathrm{i}$ jeffektivnost' farmakoterapii [Interaction of drugs and the effectiveness of pharmacotherapy]. Megapolis, Kharkov (in Russian).

Gao, W., Alcauter, S., Elton, A., Hernandez-Castillo, C. R., Smith, J. K., Ramirez, J., \& Lin, W. (2015). Functional network development during the first year: Relative sequence and socioeconomic correlations. Cerebral Cortex, 25, 2919-2928.

Gradwohl, G., Berdugo-Boura, N., Segev, Y., \& Tarasiuk, A. (2015). Sleep/wake dynamics changes during maturation in rats. PLOS One, 10(4), e0125509.

Griffen, T. C., Haley, M. S., Fontanini, A., \& Maffei, A. (2017). Rapid plasticity of visually evoked responses in rat monocular visual cortex. PLOS One, 12(9), $\mathrm{e} 0184618$

Howe, W. M., Gritton, H. J., Lusk, N. A., Roberts, E. A., Hetrick, V. L., Berke, J. D., \& Sarter, M. (2017). Acetylcholine release in prefrontal cortex promotes gamma oscillations and theta-gamma coupling during detection. Journal of Neuroscience, 37(12), 3215-3230.

Kocharyan, A., Fernandes, P., Tong, X. K., Vaucher, E., \& Hamel, E. (2008). Specific subtypes of cortical GABA interneurons contribute to the neurovascular coupling response to basal forebrain stimulation. Journal of Cerebral Blood Flow and Metabolism, 28, 221-231.

Lopes da Silva, F. H., Gonçalves, S. I., \& De Munck, J. C. (2009). Electroencephalography (EEG). Encyclopedia of Neuroscience, 2009, 849-855.

Makhmudova, N. S. (2013). Bioelektricheskiy profil' zritel'noy i sensomotornoy oblastey kory mozga krys razlichnogo vozrasta, plodnyy period beremennosti proshedshikh $\mathrm{v}$ usloviyakh gipokenezii [The bioelectric profile of the visual and sensorimotor areas of the cerebral cortex of rats of different ages, the gestational period of gestation passed under hypokinesia]. Sibirskiy Meditsinskiy Zhurnal, 3, 36-38 (in Russian).

Man'kovskiy, N. B., \& Kuznetsova, S. M. (2013). Vozrastnyye izmeneniya neyrotransmiternykh sistem mozga kak faktor riska tserebrovaskulyarnoy patologii [Age-related changes in the neurotransmitter systems of the brain as a risk factor for cerebrovascular disease]. Zhurnal Nevrologii im. B. M. Man'kovskogo, 2, 5-13 (in Russian).

Marshall, C. A. G., Suzuki, S. O., \& Goldman, J. E. (2003). Gliogenic and neurogenic progenitors of the subventricular zone: Who are they, where did they come from, and where are they going. Glia, 43, 52-61.

McDougall, S., Vargas Riad, W., Silva-Gotay, A., Tavares, H. S., Harpalani, D., Li, G. L., \& Richardson, H. N. (2018). Myelination of axons corresponds with faster transmission speed in the prefrontal cortex of developing male rats. eNeuro, 5(4), e0203-18.

Mengler, L., Khmelinskii, A., Diedenhofen, M., Po, C., Staring, M., Lelieveldt, B. P., \& Hoehn, M. (2014). Brain maturation of the adolescent rat cortex and striatum: Changes in volume and myelination. Neurolmage, 84, 35- 44

Meyer, H. C., \& Bucci, D. J. (2014). The ontogeny of learned inhibition. Learning and Memory, 21(3), 143-152.

Mizin, V. V., Lyashenko, V. P., \& Lukashov, S. M. (2017). Vzayemozv'yazok mizh rivnem kortykosteronu ta dehidroepiandrosteron-sul'fantom $\mathrm{v}$ syrovattsi krovi shchuriv riznoho viku ta stati [The relationship between the level of corticosterone and dehydroepiandrosterone sulfate in the blood serum of rats of different age and sex]. Visnyk Zaporiz'kyy Natsional'nyy Universytet, 2, 67-74 (in Ukrainian).

Mizin, V. V., Lyashenko, V. P., \& Lukashov, S. M. (2018). Zminy potuzhnostey elektrychnoyi aktyvnosti motornoyi zony kory holovnoho mozku samok shchuriv riznoho viku [Power changes in electrical activity of motor zone of the main brain of female rats of different age]. Visnyk Cherkas'kyy Universytet, Biolohichni Nauky, 1, 105-113.

Murzin, O. B., Lyashenko, V. P., \& Zadorozhnaya, G. A. (2015). Zminy bioelektrychnoyi aktyvnosti kory holovnoho mozku shchuriv, pid vplyvom vykhrovoho impul'snoho mahnitnoho polya [Changes in the bioelectric activity of rat cerebral cortex, under the influence of a vortex pulsed magnetic field] Visnyk Problem Biolohiyi i Medytsyny, 118, 377-381 (in Ukrainian).

Naber, P. A., Witter, M. P., \& Lopes da Silva, F. H. (2000). Differential distribution of barrel or visual cortex. Evoked responses along the rostro-caudal axis of the peri- and postrhinal cortices. Brain Research, 877, 298-305. 
Obermayer, J., Verhovy, M. B., Luchicchi, A., \& Mansvelder, H. D. (2017). Cholinineryic modulation of cortical microcircuits is layer-specific: Evidence from rodent, monkey and human brain. Frontiers in Neural Circuits, 100, 1-12.

Paxinos, G., \& Watson, C. (2013). The rat brain in stereotaxic coordinates. 7th ed. Academic Press.

Pirttimaki, T. M., Sims, R. E., Saunders, G., Antonio, S. A., Codadu, N. K., \& Parri, H. R. (2017). Astrocyte-mediated neuronal sychronization properties revealed by false gliotransmitter release. Journal of Neuroscience, 37(41), 9859-9870.

Schliebs, R., \& Arendt, T. (2011). The cholinergic system in aging and neuronal degeneration. Behavioral Brain Research, 221, 555-563.

Semple, B. D., Blomgren, K., Gimlin, K., Ferriero, D. M., \& Noble-Haeusslein, L. J. (2013). Brain development in rodents and humans: Identifying benchmarks of maturation and vulnerability to injury across species. Progress in Neurobiology, 1268, 1-16.

Shumilova, T. E., Smirnov, A. G., \& Sheshkov, V. I. (2015). Activity and circulatory effects of nitrite in the rat cerebrum. Biology Bulletin, 42(2), 139-144.

Sun, W., McConnell, E., Pare, J. F., Xu, Q., \& Chen, M. (2013). Glutamate-dependent neuroglial calcium signaling differs between young and adult brain. Science, 339, 197-200.

Tarokh, L., Carskadon, M. A., \& Achermann, P. (2010). Developmental changes in brain connectivity assessed using the sleep EEG. Neuroscience, 171(2), $622-634$
Tucker, A. M., Aquilina, K., Chakkarapani, E., Hobbs, C. E., \& Thoresen, M. (2009). Development of amplitude-integrated electroencephalography and interburst interval in the rat. Pediatric Research, 65(1), 62-67.

Turic'ka, T. G., Lukashov, S. M., \& Lyashenko, V. P. (2016). Efekty vplyvu khronichnoyi kofeyinovoyi alimentatsiyi na pokaznyky fonovoyi elektrychnoyi aktyvnosti neokorteksu shchuriv [Effects of chronic caffeine alimentation on the performance indicators of rat neocortex background electrical activity]. Experimental Physiology and Biochemistry, 75(3), 11-16 (in Ukrainian).

Vorob'eva, T. M., \& Koljadko, S. P. (2007). Jelektricheskaja aktivnost' mozga (priroda, mehanizmy, funkcional'noe znachenie) [The electrical activity of the brain (the nature, mechanisms, functional significance)]. Eksperimental'naja i Klinicheskaja Medicina, 2, 4-11 (in Ukrainian)

Wonders, C. P., \& Anderson, S. A. (2006). The origin and specification of cortical interneurons. Nature Reviews Neuroscience, 7(9), 687-696.

Zapadnjuk, I. P., Zapadnjuk, E. A., Zaharija, E. A., \& Zapadnjuk, B. V. (1983). Laboratornye zhivotnye: Razvedenie, soderzhanie, ispol'zovanie v eksperimente [Laboratory animals: Breeding, content, use in experiment]. Vishha Shkola, Kyiv (in Russian)

Zhang, Z. W. (2006). Postnatal development of the mammalian neocortex: Role of activity revisited. Canadian Journal of Neurological Science, 33, 158-169. 